\title{
Fostering EFL Learners' Grammar Achievement Using Recasts and Meta-linguistic Awareness Error Correction Feedbacks
}

\author{
Elham Barzang \\ Department of Foreign Languages \\ Kerman Branch, Islamic Azad University, Kerman, Iran
}

Received: November 2, 2019 Accepted: December 15, 2019 Published: December 17, 2019

doi:10.5296/jsel.v8i1.16065 URL: https://doi.org/10.5296/jsel.v8i1.16065

\begin{abstract}
The current study examines the effect of recasts and meta-linguistic error correction feedbacks and changes in EFL learners' English language grammar achievement. The participants were fifty (25 in each group) intermediate-level EFL learners at an English language institute. This quantitative experimental study was implemented on the basis of pre-test-post-test equivalent-group design. After administrating the CPT, 50 students (based on the Cambridge Assessment Criteria) who were randomly and equally assigned to recast and meta-linguistic awareness group (25students in each group) were selected as the sample of this study.The data were collected through classroom grammar test (pre- and post-tests). Both groups promoted in terms of grammar achievement, but the findings supported the superiority of grammar development in meta-linguistic group. The results revealed higher scores for explicitly corrected (meta-linguistic awareness) learners than implicitly corrected (recasts) ones. The findings lend support to the argument concerning the role of meta-linguistic awareness in language learning.
\end{abstract}

Keywords: Grammar achievement, recasts, meta-linguistic Awareness, error correction feedbacks 


\section{Introduction}

Error correction has always been a very important step in the learning process. In the fields of education and applied linguistics, it is widely believed that correcting feedbacks influence teaching and learning process.

Different studies suggest that future research on error correction look for individual learner differences, which influence whether and how learners process the feedback they receive (Sheen, 2011, p.159), to track EC mechanisms and its effects (Kim, 2004; Mackey, 2006; Rezaei \& Mozaffari, 2011; Russell, 2009; Yang \& Lyster, 2010). Corrective feedback in the form of recasts has attracted considerable attention from SLA theorists and researchers and has also been investigated in a number of descriptive and experimental studies (for recent overviews, see Ellis \& Sheen, 2006; Leeman, 2007;Nicholas, Lightbown, \& Spada, 2001; Russell \& Spada, 2006). Yet, whether and towhat extent recasts facilitate learning remains a controversial issue (e.g., Long, 2006; Lyster, 2007). Recasts are expected to shape students' awareness of structure while their main focus is on meaning/message. Consequently, it is believed that recasts make an ideal context for learning to happen (Doughty, 2001; Long, 1996).

But, review of literature shows limited empirical support for this claim, especially in meaning-centered instructional contexts. Lyster (1998b, 2002, 2004) and his colleagues have mentioned that recasts are not efficient, because learners in communicative settings do not notice the corrections and, therefore, do not use them. His claim that recasts do not promote noticing and thus do not facilitate acquisition is substantiated by recent classroom studies (Ammar \& Spada, 2006; Lyster, 2004) that show recasts to be less effective than other types of corrective feedback or do not show any learning (Ellis, 2007; Ellis, Loewen \& Erlam, 2006; Sheen, 2006a). These studies suggest that recasts of the more implicit kind are not salient and are not attended to by learners. In contrast, studies that have investigated recasts in laboratory settings have demonstrated that recasts are facilitative of second language (L2) development (e.g., Han, 2002; Long, Inagaki, \& Ortega, 1998; Mackey \& Oliver, 2002; Mackey \& Philp, 1998).

The results reported by these studies show differences in the construction of the studies that have investigated recasts (Ellis \& Sheen, 2006). Relevant design variables include the research setting (i.e., classroom versus laboratory), the specific interaction settings in which the recasts occur, their definition and operationalization, their linguistic realization, their degree of implicitness/ explicitness, how their effect on learning has been measured, and learner characteristics. Thus, before any firm conclusions can be drawn about the efficacy of recasts, there is a need for more carefully designed studies that systematically control for these variables. A design variable that has received little attention from researchers to date is individual learner factors, with the notable exception of Mackey, Philp, Egi, Fujii, and Tatsumi (2002), who explored working memory in relation to the efficacy of recasts in a dyad setting. Other factors such as language anxiety might affect the impact that recasts have on learners' responses (i.e., on uptake) and on L2 learning. Language anxiety has been shown to be significantly related to various L2 criterion measures (Horwitz, 2001). 


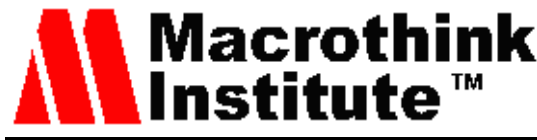

The effect of learning under explicit and implicit conditions has long been a controversial issue in the field of psychology. Most experimental studies in this area (Reber, 1976, 1993; Reber and Allen, 1978; Zizak and Reber, 2004) show that learning entails complex stimuli without conscious awareness. Most of these studies used artificial languages in their tasks as stimuli. However, in the domain of second language acquisition, where natural languages are used, it is not clear how readily these findings can be generalized. In second language acquisition, the main body of research has been very much in response to Krashen's claim that learners only learn through unconscious acquisition. Learning, he claims, which is conscious, does not lead to acquisition, which is unconscious, and acts only as a monitor. Conversely, some other researchers (Ellis, 1991; Schmidt, 1990, 1994, 2001; Schmidt and Frota, 1986) believe that learner attention is essential for focus on forms to be beneficial to learners. Some of these researchers go so far as to claim that subliminal learning is impossible and that learning is the product of the conscious noticing of forms.

A more important issue here is the degree of explicitness and implicitness of learning. As Robinson (1996, p. 7) argues, "engaging in such research is likely to provide a clearer individual base for the speculations of second language theorists regarding the extent to which unconscious learning of forms is, or is not, possible". Moreover, having an idea of the extent to which explicit and implicit error correction can be effective in restructuring the learners' interlanguage is theoretically and pedagogically critical: It may provide a clear understanding of how the human cognitive system operates when acquiring a second language.

Also, it may provide practitioners with better strategies in choosing when to correct the learners explicitly and when to do so implicitly. Explicit correction refers to the process of providing the learner with direct forms of feedback. According to Carroll and Swain (1993), teachers can explicitly state that the learners' utterance is wrong. By doing this, they direct the attention of the learner to the erroneous point. Explicit correction in this study consists of metalinguistic explanation of the erroneous structure. Implicit correction refers to the process of providing the learner with indirect forms of feedback. Learners need to deduce from the evidence that the form of their utterance is responsible for the comprehension problem. The implicit feedback provided to the learner in the present research is in the form of recast - the correct reformulation of the learners' erroneous utterances.

In Carroll and Swain (1993) and Carroll (2001), direct explicit feedback outperformed all other types of correction. Formal grammatical explanation was more effective than meaning-focussed debriefing in Muranoi (2000) study. Havranek and Cesnik (2003) found that recasts were the least effective type of correction in their study. Lyster (2004) reported that corrective prompts were more effective than recasts. Moreover, there is evidence (Nagata, 1993; Rosa and Leow, 2004) that detailed metalinguistic feedback works better than less detailed metalinguistic feedback. In addition to the laboratory studies, some classroom research studies, conducted by Doughty (1991), Leow (1998), and Scott (1989, 1990) have also mentioned that explicit correction is more effective than implicit correction.Therefore, the present study specifically extends prior research on oral CF and L2 learner grammar achievement, applying implicit (recasts) and explicit (meta-linguistic awareness) path of 
correcting errors it traces how teachers' error corrections affect EFL students' grammar development.

\section{Literature Review}

Several recent studies of adult ESL students (Lee, 2013; Han \& Jung, 2007; Panova \& Lyster, 2002; Suzuki, 2004) have shown positive associations between oral corrective feedback, learner repair, and uptake in adult ESL classrooms. Most of these studies use Lyster and Ranta's (1997) taxonomy of CF, which identifies six feedback moves: recasts, explicit correction, clarification requests, metalinguistic feedback, elicitation, and repetition. Studies following this approach have assessed the outcomes of certain types of CF on L2 development. For instance, Ellis, Loewen, and Erlam (2006) compared the efficacy of implicit CF (recasts) and explicit CF (metalinguistic feedback), while Ellis (2007) examined the extent to which recasts and metalinguistic feedback influenced the effects of CF on various grammatical structures. Likewise, Yang and Lyster's (2010) study compared the effectiveness of recasts and prompts (including clarification requests, metalinguistic feedback, elicitation, and repetition), and Chu's (2011) study juxtaposed output-promoting CF (clarification requests, metalinguistic feedback, elicitation, and repetition) and input-providing CF (explicit correction and recasts). While these studies offer useful tools for targeting CF to certain tasks or certain students, they ignore how oral CF might influence L2 learners' anxiety, which can influence their oral English development both positively and negatively.

Recasts constitute one kind of corrective feedback. They consist of targetlike reformulations of the errors that learners commit in the course of communicative activities. As noted earlier, they have been the subject of intense study by SLA researchers. For example, in the last decade alone (from 1997 to 2007), there have been more than 40 published studies that either investigated recasts in isolation or as one of several types of corrective feedback/interactional feedback (see Ellis\&Sheen, 2006; Leeman, 2007; Mackey, 2007; Russell\&Spada, 2006, for a recent overview). There have also been a number of earlier studies, reviewed in Long (1996). The interest in recasts is due to the fact that they are of considerable theoretical interest to SLA researchers and also of pedagogical significance.

On the theoretical front, recasts have served as a vehicle for investigating the role of negative evidence (i.e., language input that provides learners with information as to what is ungrammatical) in L2 learning. Recast studies have been designed to test whether learners need negative feedback or just positive input for acquisition to take place (e.g., Ayoun, 2001; Leeman, 2003; Long et al.,1998). Some studies have used recasts (viewed as a form of implicit negative feedback - although whether in fact they are is a matter of dispute; see Sheen, 2006b) in order to test whether implicit feedback promotes the development of implicit or explicit knowledge or both (e.g., Ellis et al., 2006; Loewen \& Nabei, 2007). Other studies have been designed to investigate whether conversational interaction containing corrective feedback (recasts and other types) results in L2 acquisition (e.g.,Mackey, 1999, 2006, 2007), in accordance with the claims of the interaction hypothesis (Long, 1996). 
On the pedagogical front, recasts are important because teachers have been observed to use them as a nonthreatening corrective feedback on their students' errors (Seedhouse, 2004). Recasts have been shown to be the most frequently occurring type of feedback in a variety of instructional settings in different countries: elementary immersion lessons in Canada, Korea, and the United States; university foreign language lessons in Australia and the United States; high school English as a foreign language (EFL) lessons in Hong Kong and Austria; adult EFL lessons in Korea; and adult ESL lessons in New Zealand and Canada, as illustrated in Lyster (2007). Given the frequency with which recasts occur in the classroom, it would be of obvious advantage to language teachers to know whether and under what conditions they facilitate acquisition.

As noted earlier, theoretical disagreement about the contribution that recasts make to learning exists, and in addition, the empirical findings have been inconsistent. In particular, the extent to which recasts have been shown to facilitate learning has differed according to whether the setting is a laboratory or a classroom. By and large, laboratory studies have found recasts to be effective, whereas a number of quasi-experimental classroom studies have not produced convincing evidence that recasts facilitate learning, with the exception of studies in which the recasts have been made very salient and have been directed repeatedly at the same linguistic feature (e.g., Doughty \& Varela, 1998). Han (2002) investigated the impact of recasts on the acquisition of tense consistency in a laboratory-type setting: She found that the recast group outperformed the control group on posttests and delayed posttests. In contrast, Ellis et al. (2006), in their classroom-based investigation of the relative effect of recasts and metalinguistic feedback on the acquisition of past tense $-e d$, found that metalinguistic feedback was superior to recasts and that recasts did not produce a significant effect on learning.

One possible reason for these mixed results might lie in the nature of the interactional contexts found in these two types of settings. In laboratory settings, recasts are provided in a dyadic context and are intensive (i.e., each learner receives a substantial number of recasts), whereas in classroom studies, they are typically provided in a teacher-fronted context and are less intensive (i.e., each learner receives only a fewrecasts). Arecent study by Lyster and Izquierdo (2007) lends support to the role played by the setting. They found that contrary to previous classroom studies, which had demonstrated no or only a limited effect for recasts, they were as effective as other feedback types in dyadic interaction with a native speaker. Oliver and Mackey (2003) found that differences in the contexts that occur within a classroom also affected how learners respond to recasts. They found that learners took notice of the corrective nature of recasts to a greater extent in lessons where language was emphasized than in contexts involving classroom management or conversational interaction.

Research has also provided evidence of several other factors influencing the value of recasts: the choice of target linguistic structure (e.g., Ishida, 2004; Long et al., 1998); learner proficiency/developmental readiness (e.g., Ammar \& Spada, 2006; Mackey \& Philp, 1998), age (e.g., Oliver, 1995, 2000); the linguistic characteristics of recasts (e.g., Carpenter, Jeon, MacGregor, \& Mackey, 2006; Loewen \& Philp, 2006; Lyster, 1998a; Mackey, Gass, \& McDonough, 2000); whether learners are literate in the L2 (e.g., Bigelow, de Mas, Hansen,\&Tarone, 2006); learners' perceptions/noticing of recasts; andwhether there is 
modified output following the recasts (e.g., Egi, 2007a; Mackey, 2006; McDonough \& Mackey, 2006).

A key factor affecting whether recasts work for acquisition is the learners' developmental readiness. Mackey and Philp (1998) investigated 35 ESL learners in a laboratory setting. The learnerswere divided into three groups-recasts, interaction, control-and were also distinguished in terms of their developmental "readiness" for learning English question formation (word order) — "readies" and "unreadies." The results showed that those learners who were developmentally ready in the recast group advanced in their ability to form questions to a greater extent than those in the interaction-only group. However, no performance differences were found between the recasts and interaction groups in the case of the "unreadies." Thus, this study indicates that corrective feedback, recasts in particular, might only be effective when learners are developmentally ready to acquire the target structure.

Another important learner-internal factor is suggested by Egi (2008), who explored the link between learners' perceptions and their uptake of recasts. She investigated 24 foreign language (FL) learners of Japanesewho received recasts of their errors in task-based interactions and participated in a stimulated-recall interview. She reported that those learners who repaired their errors following recasts recognized the corrective force of the recasts and also noticed the gap between their erroneous output and the target form. Egi (2007b) also demonstrated that learners who noticed the gap (i.e., perceived recasts as negative as well as positive evidence) outperformed those learners who did not perceive recasts as corrective. Her findings suggest a direct relationship among uptake, noticing, and L2 learning and lend support to Mackey's (2006) conclusion that interactional feedback helps L2 acquisition when learners notice the corrective force of the feedback and attend to the gap between their own erroneous forms and the target language forms. Other researchers have investigated learner-external variables such as the linguistic aspects of recasts. Loewen and Philp (2006), for example, investigated the effect of different characteristics of recasts (e.g., linguistic focus, length, number of changes, segmentation) on individual learners' acquisition, as measured by tailor-made tests. They found that those recasts with explicit linguistic characteristics were more likely to result in learning.

\section{Research Questions}

This study attempts to answer the following research questions:

RQ1: How does explicit error correction (meta-linguistic Awareness) affect EFL learners' grammar development?

RQ2: How does implicit error correction (recasts) affect EFL learners' grammar development? 


\section{Methodology}

\subsection{Participants}

The population of this study was intermediate female EFL students (12-18 years old) at a private English Language institute in Kerman, Iran. A Cambridge Placement Test (CPT) was used to have almost homogenous groups. After administrating the CPT, 50 students (based on the Cambridge Assessment Criteria) who were randomly and equally assigned to the explicit and implicit groups (25students in each group) were selected as the sample of this study.

\subsection{Instruments}

The instrument applied in this study was a teacher-made test of grammar (pre-test \& post-test). The grammar test consisted of recognition, grammatical judgement, and production test items. To consider the internal consistency reliability (to evaluate the degree to which different test items that probe the same construct produce similar results), split-half reliability as a subtype of internal consistency reliability was used. The process of obtaining split-half reliability begun by splitting in half all items of the test that were intended to probe the same area of knowledge in order to form two sets of items(odd \& even). The entire test was administered, the total score for each set was computed, and finally the split-half reliability was obtained by determining the correlation between the two total set scores. The reliability of the test was 0.79 (pre-test) and 0.81(post-test).

To check the validity, the grammar test was used in a way to test the topics being covered at class to follow the content relevance and content coverage validity (simple present, present continuous, simple past, \& past continuous). The grammar test was also piloted on a sample of 10 pre- intermediate English students similar to that of the main study. According to the results of the pilot study and regarding the opinions of some experienced instructors of grammar, the questions were analyzed and changed to increase the test reliability and validity.

\subsection{Research Procedure}

This study was implemented on the basis of pre-test-post-test equivalent-group design and the following steps were taken for data collection. In the first stage, a Cambridge Placement Test (CPT) was used to have almost homogenous groups. After administrating the CPT, 50 students (based on the Cambridge Assessment Criteria) who were randomly and equally assigned to recast and meta-linguistic awareness group (25students in each group) were selected as the sample of this study.

In the second stage, both groups took the grammar pre-test as a measure of the participants' grammar knowledge of the selected English grammar points (simple present, present continuous, simple past, $\&$ past continuous). In the third stage, both groups were independently taught the grammar points based on a planned time schedule, three days a week for one hour (3months). The only difference between the implicit and explicit groups was using explicit corrective explanations in meta-linguistic awareness group, and repeating the words back to the student, usually with different intonation or form, or as a question in recast group. The taught grammar points were simple present, present continuous, simple past, and past 
continuous. To nullify the potential effect of methodology, both groups were taught by the same instructor (researcher). Finally, the post-test was administered in the two groups after the treatment sessions.

\section{Results}

In order to examine the effect of error correction on EFL learners' grammar development, paired sample t-test and independent t-test were run. The result of the paired sample t-test analysis did not show a significant difference in the mean scores for the pre-test ( $M 1=4.40$, $\mathrm{SD} 1=1.53)$ and post-test of implicit group $\left(\mathrm{M}_{2}=7.60, \mathrm{SD}_{2}=1.73\right), \mathrm{t}=-10.67, \mathrm{df}=24, \mathrm{p}<0.01$, and the effect size was $\mathrm{ES}=1.96$ and $\mathrm{r}=0.70$. But the results strongly confirmed a significant difference in the mean scores for explicit group in pre- test $\left(\mathrm{M}_{1}=4.48, \mathrm{SD}_{1}=1.45\right)$, and post-test $\left(\mathrm{M}_{2}=12.76, \mathrm{SD}_{2}=1.45\right), \mathrm{t}=-19.79, \mathrm{df}=24, \mathrm{p}<0.01$., and the effect size was $\mathrm{ES}=5.71$ and $\mathrm{r}=0.944$.

The result of the independent t-test analysis did not show a significant difference in the mean scores for implicit $(\mathrm{M} 1=4.40, \mathrm{SD} 1=1.53)$ and explicit group $\left(\mathrm{M}_{2}=4.48, \mathrm{SD}_{2}=1.45\right)$ pre- test, $\mathrm{t}=-0.19, \mathrm{df}=48 . \mathrm{P}>0.05$. But the results strongly confirmed a significant difference in the mean scores for implicit $\left(\mathrm{M}_{1}=7.60, \mathrm{SD}_{1}=1.73\right)$, and explicit group $\left(\mathrm{M}_{2}=12.76, \mathrm{SD}_{2}=1.45\right)$ in post-test, $\mathrm{t}=-11.42, \mathrm{df}=, 48 \mathrm{p}<0.01$, and the effect size was $\mathrm{ES}=3.24$ and $\mathrm{r}=0.851$.

Table 1. Paired T Test of Implicit and Explicit Error Corrections

\begin{tabular}{|c|c|c|c|c|c|c|}
\hline Time & $\mathbf{N}$ & Mean & Std.Deviation & T-Test & df & P-Value \\
\hline $\begin{array}{c}\text { Implicit } \\
\text { group } \\
\text { pre-test }\end{array}$ & 25 & 4.40 & 1.53 & \multirow{2}{*}{-10.67} & \multirow{2}{*}{24} & \multirow{2}{*}{0.0005} \\
\hline $\begin{array}{c}\text { Implicit } \\
\text { group } \\
\text { post-test }\end{array}$ & 25 & 7.60 & 1.73 & & & \\
\hline Time & $\mathbf{N}$ & Mean & Std.Deviation & T-Test & df & P-Value \\
\hline $\begin{array}{c}\text { Explicit } \\
\text { group } \\
\text { pre-test }\end{array}$ & 25 & 4.48 & 1.45 & \multirow{2}{*}{-19.79} & \multirow{2}{*}{24} & \multirow{2}{*}{0.0005} \\
\hline $\begin{array}{c}\text { Explicit } \\
\text { group } \\
\text { post-test }\end{array}$ & 25 & 12.76 & 1.45 & & & \\
\hline
\end{tabular}


Table 2. Independent T Test of Implicit and Explicit Error Corrections

\begin{tabular}{|c|c|c|c|c|c|c|}
\hline & & & & T-Test & df & P-Value \\
\hline Group \& time & $\begin{array}{r}\text { Total } \\
\text { number }\end{array}$ & Mean & Std.Deviation & \multirow{3}{*}{-0.19} & \multirow{3}{*}{48} & \multirow{3}{*}{0.9} \\
\hline $\begin{array}{l}\text { Implicit } \\
\text { Pre-test }\end{array}$ & 25 & 4.40 & 1.53 & & & \\
\hline \multirow[t]{2}{*}{$\begin{array}{l}\text { Explicit } \\
\qquad \text { Pre-test }\end{array}$} & 25 & 4.48 & 1.45 & & & \\
\hline & \multicolumn{3}{|c|}{ Decontextualized } & T-Test & df & P-Value \\
\hline Group\& time & $\begin{array}{r}\text { Total } \\
\text { number }\end{array}$ & Mean & Std.Deviation & \multirow{3}{*}{-11.42} & \multirow{3}{*}{48} & \multirow{3}{*}{0.0005} \\
\hline $\begin{array}{l}\text { Implicit } \\
\text { Post-test }\end{array}$ & 25 & 7.60 & 1.73 & & & \\
\hline $\begin{array}{l}\text { Explicit } \\
\text { Post-test }\end{array}$ & 25 & 12.76 & 1.45 & & & \\
\hline
\end{tabular}

\section{Discussion and Conclusion}

The current study attempted to determine the effect of explicit (meta-linguistic awareness) and implicit (recast) correction feedbacks on grammar achievement of EFL learners. The results indicated that explicit correction was significantly more effective than the implicit correction. The results lend support to Schmidt and Frota's (1986) noticing hypothesis. It is as a result of noticing that learners are able to process the corrective feedback. Also, it is as a result of understanding their errors that learners are more likely able to restructure their interlanguage. Explicit error correction creates more understanding and thus facilitates learning better than implicit error correction (Varnosfadrani \& Basturkmen, 2009).

One possible reason for better performance in the explicit may have been that it was more effective in raising awareness of corrected feature in the learners. Explicit correction involved metalinguistic feedback as well as the provision of the correct forms, but implicit correction involved only provision of the correct form. Considering the crucial role of attention in learning (Doughty, 2001; Schmidt, 2001), awareness may have been the main cause for the better performance of the explicit correction group over the implicit. Schmidt (1990) believes that subliminal learning is impossible, and that intake is what learners consciously notice ( $\mathrm{p}$. 149). He also believes that "attention controls access to conscious knowledge" (Schmidt, 
1994 p. 176), allowing the new features to be learned.

The explicit correction of learners' errors may have triggered the learners' noticing of gaps between the target form and their existing interlanguage forms and this led them to restructure their interlanguage. Moreover, as rod Ellis (1991) claims, in order for acquisition to take place, learners must notice, compare, and integrate the feedback. Therefore, the explicit correction in this study may not only have pushed the learners to notice the target feature, but also may have created a situation in which they compared the noticed target feature with their own interlanguage rules and thereby were able to incorporate it into their interlanguage. On the other hand, implicit correction probably did not trigger noticing to the same extent as the explicit correction did, and consequently may not have created a situation in which the learners could compare the target forms with their existing interlanguage forms in order to incorporate them into their interlanguage systems.

\section{References}

Chan, D. Y., \& Wu, G. (2004). A study of foreign language anxiety of EFL elementary school students in Taipei County. Journal of National Taipei Teachers College, 17, 287-320.

Chu, R. (2011). Effects of teacher's corrective feedback on accuracy in the oral English of English-Majors college students. Theory and Practice in Language Studies, 1(5), 454-459.

Cook, V. (1993). Linguistics and second language acquisition. London: Macmillan Press.

DeKeyser, R. M. (1993). The effect of error correction on L2 grammar knowledge and oral proficiency. The Modern Language Journal, 77, 501-514.

Ellis, R. (2007). The differential effects of corrective feedback on two grammatical structures. In A. Mackay (Ed.), Conversational interaction in second language acquisition: A collection of empirical studies (pp. 407-452). Oxford: Oxford University Press.

Ellis, R. (2009). Corrective feedback and teacher development. L2 Journal, 1, 3-18.

Ellis, R., Loewen, S., \& Erlam, R. (2006). Implicit and explicit corrective feedback and the acquisition of L2 grammar. Studies in Second Language Acquisition, 28, 339-368.

Han, J., \& Jung, J. (2007). Patterns and preferences of corrective feedback and learner repair. Korean Journal of Applied Linguistics, 23, 243-260.

Horwitz, E. K. (2001). Language anxiety and achievement. Annual Review of Applied Linguistics, 21, 112-126.

Horwitz, E. K., Horwitz, M. B., \& Cope, J. (1986). Foreign language classroom anxiety. The Modern Language Journal, 70, 125-132.

Kim, J. H. (2004). Issues of corrective feedback in second language acquisition. Teachers College, Columbia University Working Papers in TESOL \& Applied Linguistics, 4(2), 1-24.

Krashen, S. (1982). Principles and practice in second language acquisition. Oxford: 
Pergamon.

Lee, E. (2013). Corrective feedback preferences and learner repair among advanced ESL students. System, 41(2), 217-230.

Lyster, R., \& Ranta, L. (1997). Corrective feedback and learner uptake: negotiation of form in communicative classrooms. Studies in Second Language Acquisition, 19, 37-66.

MacIntyre, P. D. (1999). Language anxiety: a review of literature for language teachers. In D. J. Young (Ed.), Affect in foreign language and second language learning (pp. 24e43). New York: McGraw Hill Companies.

Mackey, A. (2006). Feedback, noticing, and second language development: an empirical study of L2 classroom interaction. Applied Linguistics, 27, 405-430.

McLaughlin, B. (1987). Theories of second-language learning. London: Edward Arnold.

Panova, I., \& Lyster, R. (2002). Patterns of corrective feedback and uptake in an adult ESL classroom. TESOL Quarterly, 36, 573-593.

Rezaei, S., \& Mozaffari, F. (2011). Corrective feedback in SLA: classroom practice and future directions. International Journal of English Linguistics, 1(1), 21-29.

Russell, V. (2009). Corrective feedback, over a decade of research since Lyster and Ranta (1997): where do we stand today? Electronic Journal of Foreign Language Teaching, 6(1), 21-31.

Sheen, Y. (2004). Corrective feedback and learner uptake in communicative classrooms across instructional settings. Language Teaching Research, 8, 263-300.

Sheen, Y. (2007). The effects of corrective feedback, language aptitude and learner attitudes on the acquisition of English articles. In A. Mackey (Ed.), Conversational interaction in second language acquisition: A collection of empirical studies (pp. 301-322). Oxford: Oxford University Press.

Sheen, Y. (2008). Recasts, language anxiety, modified output and L2 learning. Language Learning, 58, 835-874.

Sheen, Y. (2011). Corrective feedback, individual differences and second language learning. New York: Springer.

Sparks, R., Patton, J., Ganschow, L., \& Humbach, N. (2009). Long-term relationships among early first language skills, second language aptitude, second language affect, and later second language proficiency. Applied Psycholinguistics, 30, 725-755.

Suzuki, M. (2004). Corrective feedback and learner uptake in adult ESL classrooms. Columbia University Working papers in TESOL \& Applied Linguistics, 4, 1-21.

Tsiplakides, I., \& Keramida, A. (2009). Helping students overcome foreign language speaking anxiety in the English classroom: theoretical issues and practical recommendations. International Education Studies, 2, 39-44. 


\section{Macrothink}

Varnosfadrani, A.D., \& Basturkmen, H. (2009). The effectiveness of implicit and explicit error correction on learners' performance. System , 37, 82-98.

Woodrow, L. (2006). Anxiety and speaking English as a second language. RELC Journal, 37(3), 308-328.

Yang, Y., \& Lyster, R. (2010). Effects of form-focused practice and feedback on Chinese EFL learners' acquisition of regular and irregular past tense forms. Studies in Second Language Acquisition, 32, 235-263.

Young, D. J. (1994). New directions in language anxiety research. In C. A. Klee (Ed.), Faces in a crowd: The individual learner in multi-section courses (pp. 3-45). Boston: Heinle \& Heinle Publishers.

Zheng, Y. (2008). Anxiety and second/foreign language learning revisited. Canadian Journal for New Scholars in Education, 1, 1-12.

\section{Copyright Disclaimer}

Copyright for this article is retained by the author(s), with first publication rights granted to the journal.

This is an open-access article distributed under the terms and conditions of the Creative Commons Attribution license (http://creativecommons.org/licenses/by/3.0/). 